\title{
Production of Low Activity Rhenium by Transmuting Tungsten Metal in Fast Reactors with Moderator
}

\section{Tsugio Yokoyama* and Masaki Ozawa}

Research Laboratory for Nuclear Reactors, Tokyo Institute of Technology, Japan

\begin{abstract}
The feasibility of rhenium (Re) production by irradiating tungsten (W) metal in a medium size fast reactor was evaluated by using a Monte Carlo code. The irradiation of W with hydride zirconium moderator in a fast reactor blanket region can produce about 50 kilograms of Re per every 3 years, which corresponds $1 \%$ of Japanese domestic annual production. The specific activity of Re recovered shows below the exemption level, and furthermore, it is decreased to the level below the natural Re specific activity when deuteride zirconium moderator is used.
\end{abstract}

\section{Keywords}

Nuclear transmutation, Tungsten, Rhenium, Specific activity

\section{Transmutation using Fast Reactors and Neu- tron Moderator}

Nuclear transmutation is defined as the change of an isotope to another. Thus the form of nuclear transmutation shows many patterns including natural disintegrations of radioactive nuclides to nuclear reactions induced by charged particles by accelerators. The practical way of nuclear transmutation is usually conducted by neutron-induced reactions in nuclear reactors.

Figure 1 shows the layout and profile of a typical prototype fast reactor (FR) core, which is employed for the evaluation of the transmutation. Table 1 lists the major specifications of the core. The profile of the fuel assembly is shown in the left hand of Figure 2 and the detailed design parameters of core components employed are listed in Table 2. The fuel material is plutonium-uranium mixed oxide located at the inner core (lower enrichment zone) and the outer core (higher enrichment zone). Some neutrons leak out to the blanket region where depleted uranium is located to breed fissile fuel by capturing leaked neutrons in the conventional design [1].

An estimated neutron balance of the FR core, where liquid sodium is used as coolant, is listed in Table 3 with that of the light water reactors (LWRs).

The neutron energy spectrum of FR cores shows faster or harder one at the core region than that of LWRs because the coolant (liquid sodium) is much heavier nuclides relative to that of water (hydrogen). Thus the average number of emitted neutrons of FRs per absorption, where the main fissile nuclide is plutonium-239, is about 2.5 , while

*Corresponding author: Tsugio Yokoyama, Research Laboratory for Nuclear Reactors, Tokyo Institute of Technology, Tokyo, 152-8550, Japan

Accepted: June 13, 2019; Published: June 15, 2019

Copyright: (C) 2019 Yokoyama T, et al. This is an open-access article distributed under the terms of the Creative Commons Attribution License, which permits unrestricted use, distribution, and reproduction in any medium, provided the original author and source are credited.

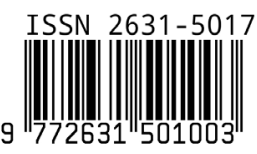

Yokoyama and Ozawa. Int J At Nucl Phys 2019, 4:012 
Table 1: Specification of fast reactor.

\begin{tabular}{|c|c|c|c|}
\hline Item & Unit & Value & Note \\
\hline 1. Reactor thermal power by fission & MW & 710 & \\
\hline 2. Coolant & & Liquid sodium & Mass density: 0.9058 \\
\hline \multicolumn{4}{|l|}{ 3. Core } \\
\hline \multicolumn{4}{|l|}{ (1) Type } \\
\hline Configuration & - & Homogeneous & \\
\hline No. of enrichment zone & - & 2 & \\
\hline \multicolumn{4}{|l|}{ (2) Number of core components } \\
\hline Core total & - & 198 & \\
\hline Inner core & - & 108 & Enrichment of Pu fissile $16 \%$ \\
\hline Outer core & - & 90 & Enrichment of Pu fissile 21\% \\
\hline Control rod & - & 19 & \\
\hline Radial blanket & - & 174 & \\
\hline Radial neutron shield & - & 324 & \\
\hline \multicolumn{4}{|l|}{ (3) Core dimension } \\
\hline Active core height & $\mathrm{mm}$ & 930 & \\
\hline Equivalent diameter & $\mathrm{mm}$ & 1788 & \\
\hline Height/Diameter & - & 0.52 & \\
\hline Core volume & 1 & 2335 & \\
\hline \multicolumn{4}{|l|}{ (4) Blanket thickness } \\
\hline Axial blanket (upper/lower) & $\mathrm{mm}$ & $300 / 350$ & \\
\hline Radial blanket equivalent thickness & $\mathrm{mm}$ & 315 & \\
\hline (5) Assembly pitch & $\mathrm{mm}$ & 115.6 & \\
\hline \multicolumn{4}{|l|}{ (6) Pu isotope ratio } \\
\hline${ }^{239} \mathrm{Pu} /{ }^{240} \mathrm{Pu} /{ }^{241} \mathrm{Pu} /{ }^{242} \mathrm{Pu}$ & - & $58 / 24 / 14 / 4$ & \\
\hline \multicolumn{4}{|l|}{ (7) $U$ isotope ratio } \\
\hline${ }^{235} \mathrm{U} /{ }^{238} \mathrm{U}$ & - & $3 / 97$ & \\
\hline
\end{tabular}

Table 2: Specification of core components.

\begin{tabular}{|l|l|l|l|}
\hline Item & Unit & Value & Note \\
\hline 1. Driver fuel & & & \\
\hline Core fuel material & - & MOX & Mixed oxide with $\mathrm{PuO}_{2}-\mathrm{UO}_{2}$ \\
\hline Core fuel pellet OD & $(\mathrm{mm})$ & 5.4 & \\
\hline Core fuel density & (\%T.D.) & 85 & \\
\hline Axial blanket material & - & depleted U & ${ }^{235} \mathrm{U} / \mathrm{U}=0.003$ \\
\hline Axial blanket pellet OD & (mm) & 5.4 & \\
\hline Axial blanket density & (\%T.D.) & 93 & \\
\hline Fuel pin cladding material & - & $\mathrm{SS} 316$ & \\
\hline
\end{tabular}




\begin{tabular}{|c|c|c|c|}
\hline No. of fuel pins per assembly & - & 169 & \\
\hline Core fuel pin OD & $(\mathrm{mm})$ & 6.5 & \\
\hline Core fuel pin cladding thickness & $(\mathrm{mm})$ & 0.47 & \\
\hline Fuel pin pitch & $(\mathrm{mm})$ & 7.9 & \\
\hline Fuel pin pitch/diameter & - & 1.22 & \\
\hline Fuel pin length & $(\mathrm{mm})$ & 2800 & F.P. gas plenum located at upper \\
\hline Axial neutron shield material & - & SS316 & - \\
\hline Axial neutron shield length & $(\mathrm{mm})$ & 645 & Volume ratio SS: $\mathrm{Na}=73: 27$ \\
\hline Duct material & - & SS316 & \\
\hline Duct inner-flat-to-flat & $(\mathrm{mm})$ & 104.6 & \\
\hline Duct thickness & $(\mathrm{mm})$ & 3 & \\
\hline Assembly length & $(\mathrm{mm})$ & 4200 & \\
\hline \multicolumn{4}{|l|}{ 2. Radial blanket assembly } \\
\hline Blanket fuel material & - & depleted U & ${ }^{235} \mathrm{U} / \mathrm{U}=0.003$ \\
\hline Blanket fuel pellet OD & $(\mathrm{mm})$ & 10.4 & \\
\hline Blanket fuel density & (\%T.D.) & 93 & \\
\hline Blanket pin cladding material & - & SS316 & \\
\hline No. of fuel pins per assembly & - & 61 & \\
\hline Blanket fuel pin OD & $(\mathrm{mm})$ & 11.6 & \\
\hline Blanket fuel pin cladding thickness & $(\mathrm{mm})$ & 0.5 & \\
\hline Blanket fuel pin pitch & $(\mathrm{mm})$ & 13.15 & \\
\hline Blanket fuel pin pitch/diameter & - & 1.135 & \\
\hline Blanket fuel pin length & $(\mathrm{mm})$ & 2800 & F.P. gas plenum located at upper \\
\hline \multicolumn{4}{|l|}{ 3. Control rod } \\
\hline Guide tube material & - & SS316 & All rod out simulated \\
\hline Guide tube OD & $(\mathrm{mm})$ & 10.4 & \\
\hline Guide tube ID & $(\mathrm{mm})$ & 10.4 & \\
\hline \multicolumn{4}{|l|}{ 4. Neutron shield } \\
\hline Material & - & SS304 & Volume ratio SS: $\mathrm{Na}=78: 22$ \\
\hline \multicolumn{4}{|l|}{ 5. Target assembly } \\
\hline No. of total pins per assembly & - & 61 & Same as radial blanket assembly \\
\hline No. of tungsten pins per assembly & - & 61 to 43 & Depend on survey case \\
\hline No. of moderator pins per assembly & - & 0 to 18 & Depend on survey case \\
\hline Tungsten pellet density & - & 19.25 & \\
\hline Zirconium hydride pellet density & - & 5.6 & $\mathrm{H} / \mathrm{Zr}$ stoichiometry $=1.7$ \\
\hline Pellet stack height & $(\mathrm{mm})$ & 930 & Same as active core height \\
\hline
\end{tabular}

that of LWRs is 2.1 due to the difference of neutron spectrum [1]. Furthermore, the neutron loss of parasitic absorption of structure and coolant per fission neutron is 0.1 in FRs, while that of LWRs is 0.5 . Thus more excess neutrons are available to utilize for transmutation if the system is designed appropriately. The studies on the transmutation using FRs are dedicated for the transmutations of minor actinides or long-lived fission products to short-lived or stable nuclides so far because these radioactive wastes are considered to be the main source of hazards in future when the geological disposal of radioactive waste is employed. 
Table 3: Estimated neutron balance of thermal and fast reactor.

\begin{tabular}{|l|l|l|}
\hline Items & Thermal Reactor & Fast Reactor \\
\hline Number of fission neutrons per one neutron capture & 2.1 & 2.5 \\
\hline To sustain chain reactions & 1.0 & 1.0 \\
\hline To be captured by coolant and structure material & 0.5 & 0.1 \\
\hline $\begin{array}{l}\text { Maximum number of neutrons available to transmutation, which are } \\
\text { used to conversion of }{ }^{238} \mathrm{U} \text { to }{ }^{239} \mathrm{Pu} \text { in conventional reactors }\end{array}$ & 0.6 & 1.4 \\
\hline Total & 2.1 & 2.5 \\
\hline
\end{tabular}
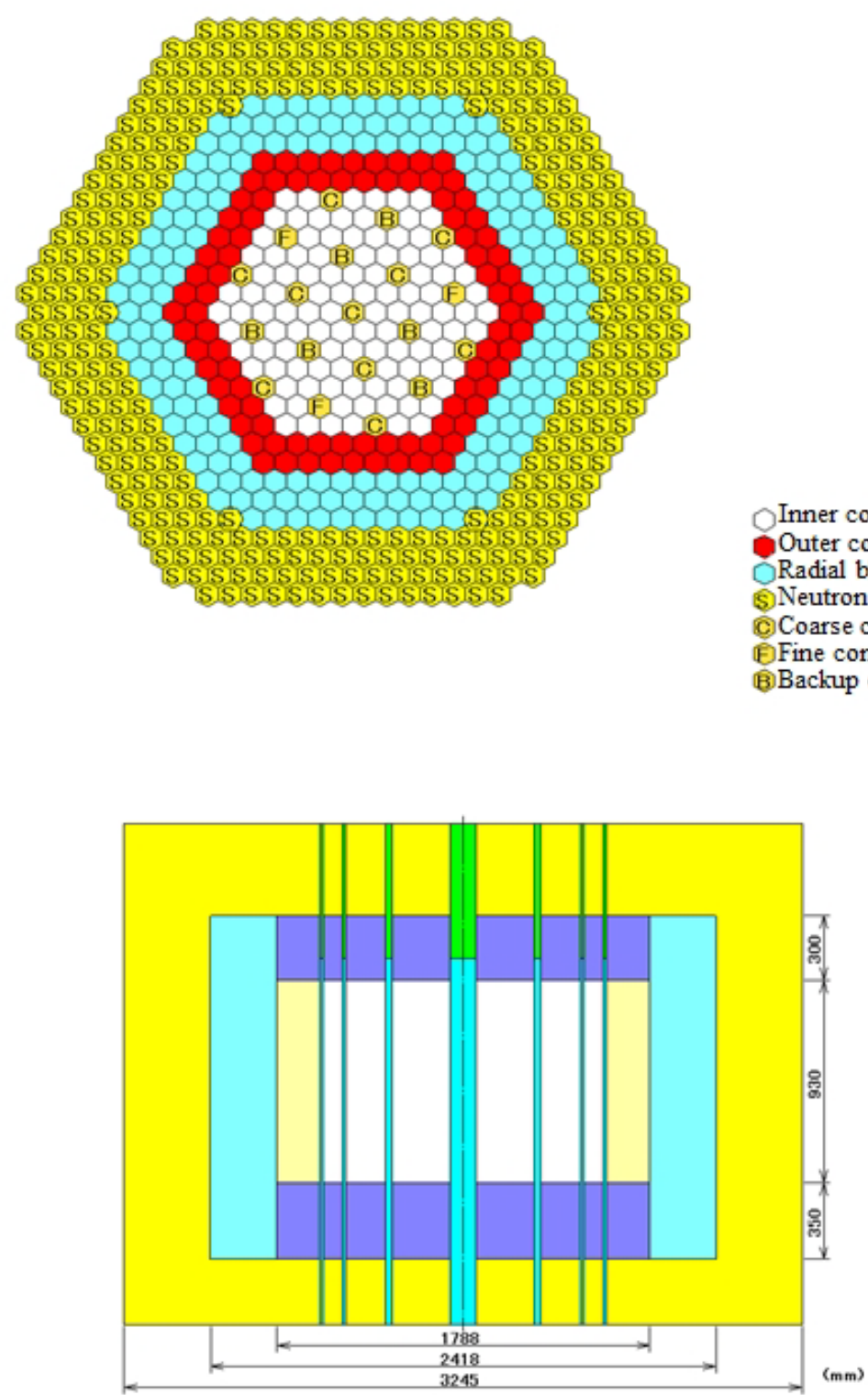

Figure 1: Core layout and profile of fast reactor.

In recent years, the demand for rhenium (Re) is growing as an additive to super alloys for jet engines. However, rhenium is one of the rarest elements in earth. The abundance of $R e$ is much smaller: $10^{-9}$ times of $\mathrm{Si}$ and $10^{-4}$ times of tungsten (W). The price of Re is about 500 times that of $\mathrm{W}$ at present. Therefore, active technology for creation of Re that we advocate has a great value.

Après ORIENT research program, newly initiated in 2011, includes transmutation of stable elements to create rare metals/RE (rare earth) elements by $(n, \gamma)$ reaction with subsequent beta decays in 


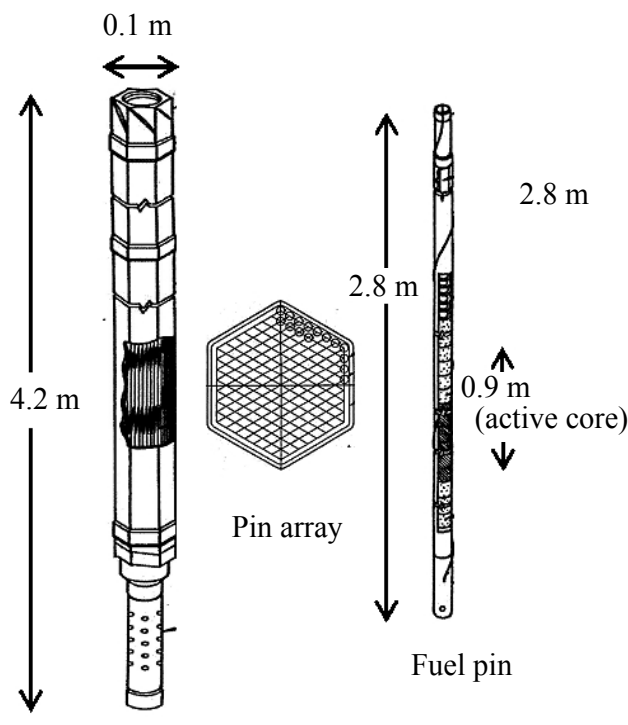

Fuel assembly

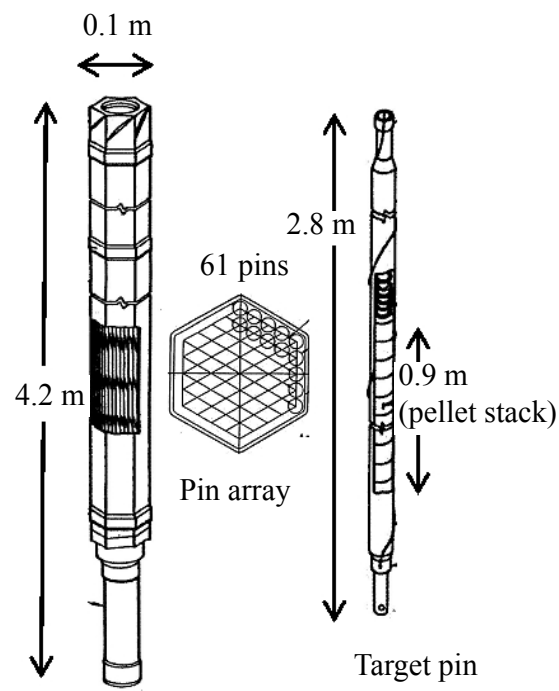

Target assembly

Figure 2: Profile of fuel and target assembly.

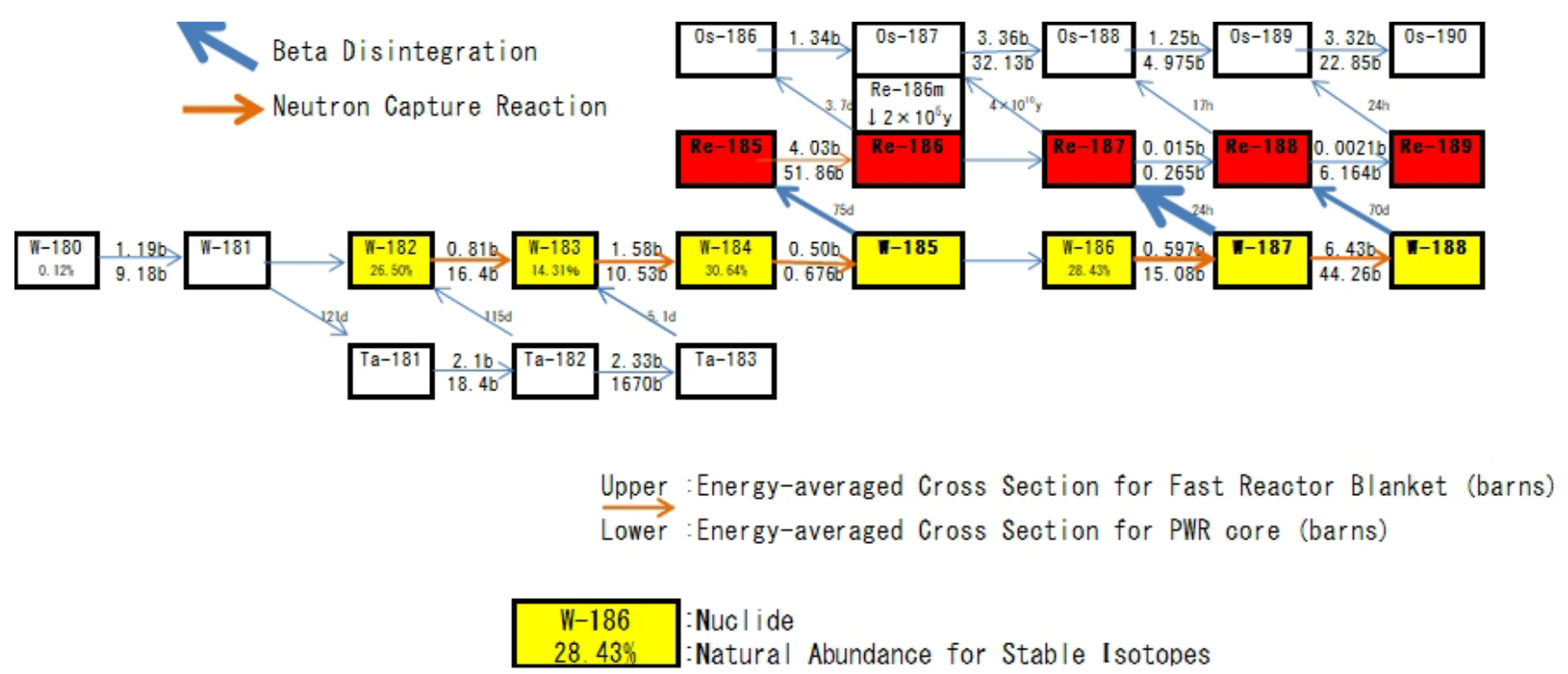

Figure 3: Nuclear transmutation scheme of tungsten (W) to rhenium (Re).

the reactors [2-4]. Re can be produced by nuclear transmutation where $\mathrm{W}$ captures neutrons and disintegrates to Re [5].

The objective of this study is to clarify the feasibility of production of Re from $\mathrm{W}$ metal in fast reactors by using neutron moderator.

The target assembly used for the W-Re transmutation is shown at the right hand of Figure 2, which is similar to the radial blanket fuel assembly located at the peripheral of the driver fuel except pellets accommodated in the pin.
In our study, we focused two points for setting the transmutation system in FRs, amount of produced Re for practical use and specific activity of Re for radiation protection. The exemption level of specific activity, that is a radioactivity level under that market use is approved, is defined by IAEA for each radioactive nuclide as $\mathrm{Bq} / \mathrm{gram}$-element [6].

Figure 3 illustrates the transmutation scheme of $W$ to Re with other related reactions in reactors. The isotope abundance of $\mathrm{W}$ indicates that, two main paths for Re production are:

(1) ${ }^{184} \mathrm{~W}$ (abundance: $31 \%$ ) to ${ }^{185} \mathrm{~W}$ by neutron 


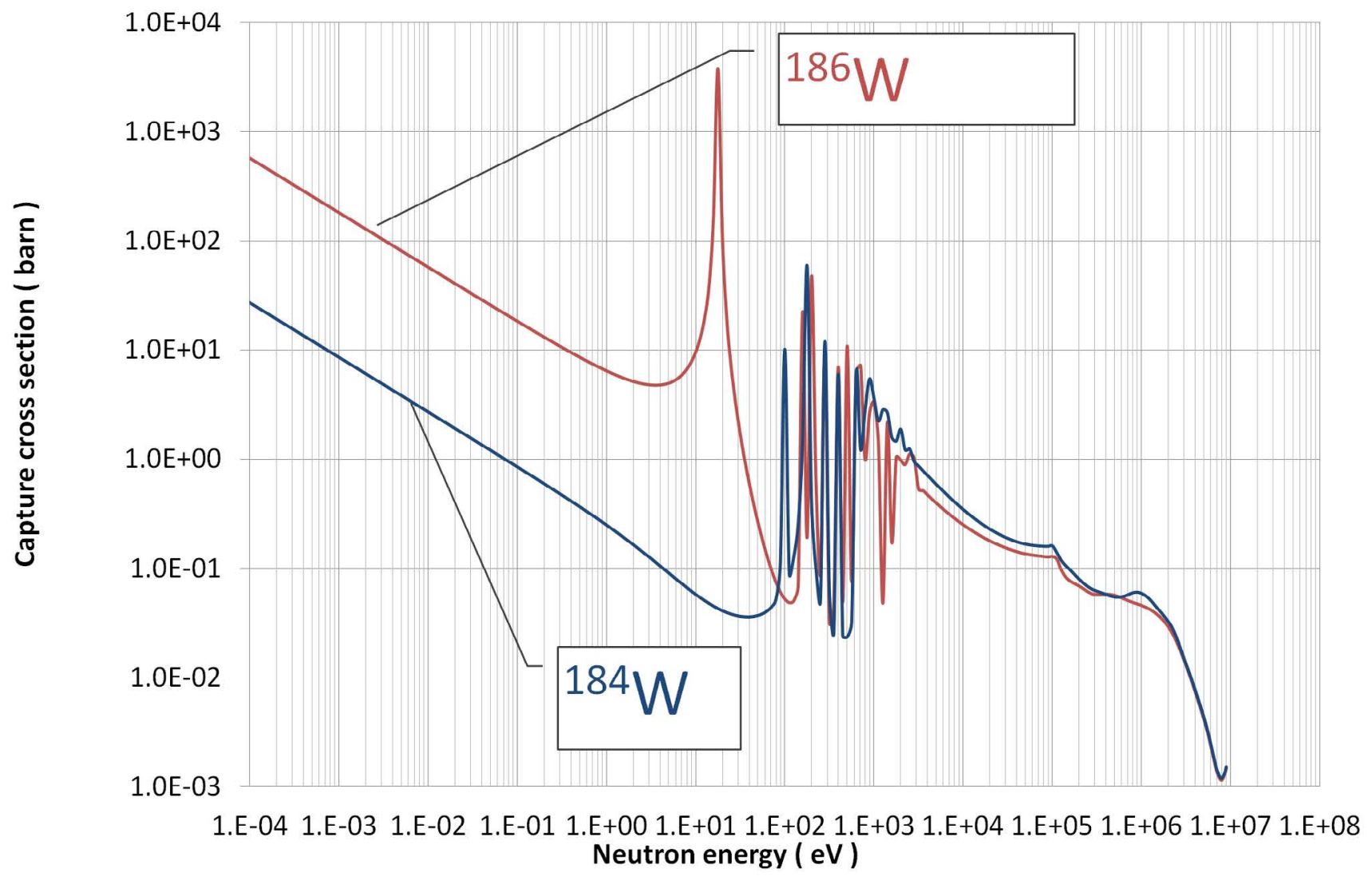

Figure 4: Capture cross section of $W$ isotopes.

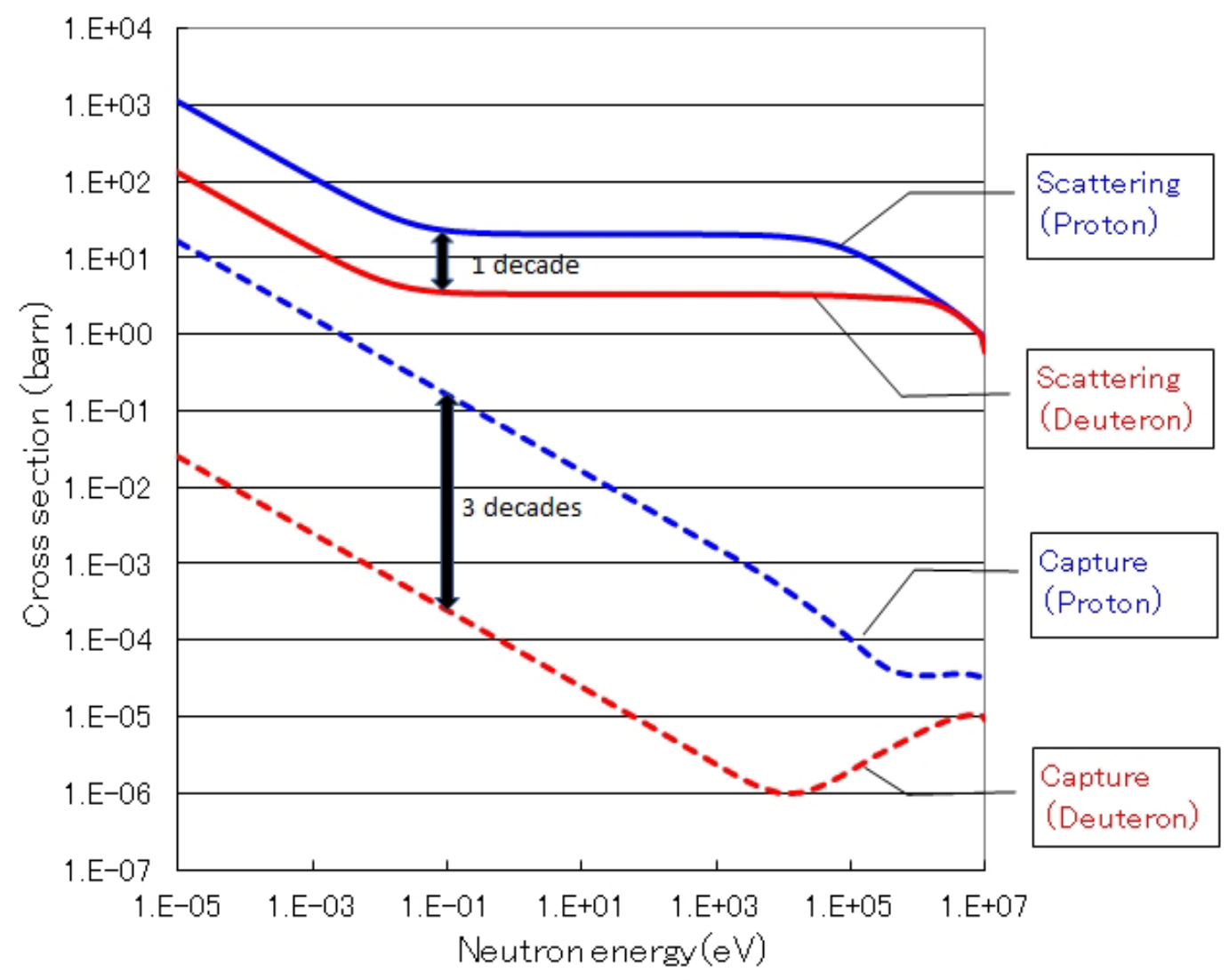

Figure 5: Cross section of hydrogen and deuteron. 
capture to ${ }^{185}$ Re by beta disintegration;

(2) ${ }^{186} \mathrm{~W}$ (abundance: $28 \%$ ) to ${ }^{187} \mathrm{Wby}$ neutron capture to ${ }^{187} \mathrm{Re}$ by beta disintegration.

The residual radioactivity produced by $\mathrm{W}$ irradiation is $\beta$ disintegration of ${ }^{187} \mathrm{Re}$ and no $\gamma$ ray emitted after a few years cooling time and the energy of emitted electron is as low as $2.64 \mathrm{KeV}$. But such feature may be troublesome if lot of $\mathrm{Re}$ is utilized worldwide as artificially produced material because the detection of no $\gamma$ ray emitted material is hard to detect out. Thus we have focused on the specific activity of the produced Re in our proposed system.

As shown in Figure 4, lower energy neutrons react with more $W$ isotopes. Figure 5 shows the scattering and absorption cross section of the typical neutron moderator nuclides, proton and deuteron. Proton has a larger scattering cross section than deuteron by 1 order while deuteron has much smaller absorption cross section. We have selected, thus, materials containing proton or deuteron as candidates for effective moderator, and zirconium hydride or zirconium deuteride are employed because zirconium can retain much hydrogen (1.7 times $\mathrm{Zr}$ or more at $600^{\circ} \mathrm{C}$ ) and have some experiences for the reactor materials in FRs.

\section{Analysis Method and Verification}

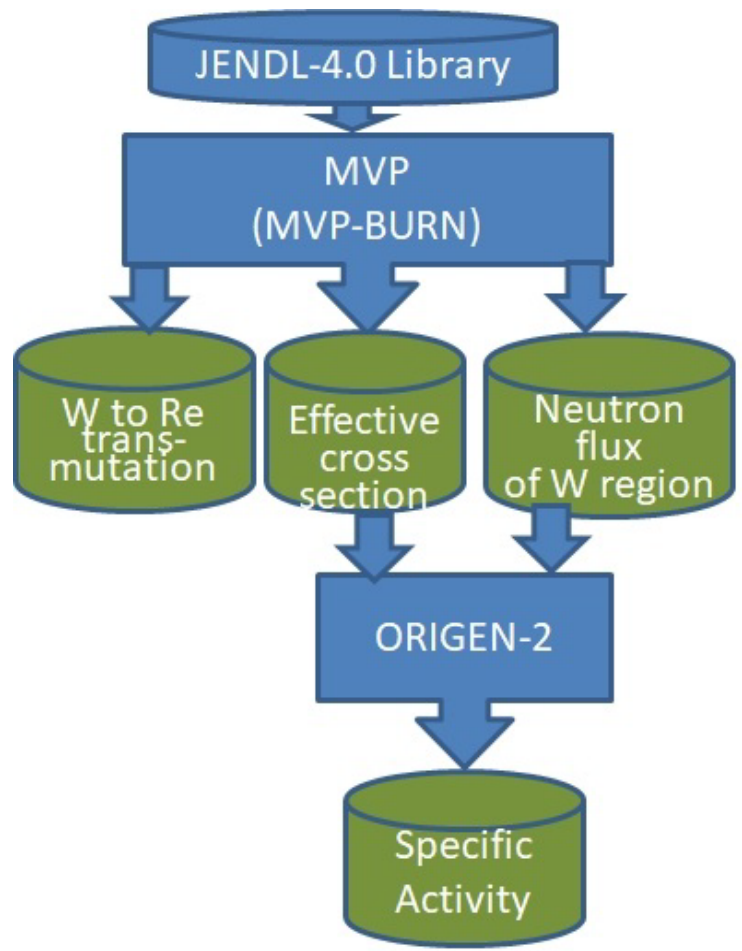

Figure 6: Analysis code system for W-Re transmutation.
The code system used in the analysis is shown in Figure 6. A continuous energy three dimensional Monte Carlo code, MVP [7] with its burn-up calculation routine MVP-BURN [8] where detailed configuration of the core components are input and the neutron energy spectra of each zone of reactors are exactly simulated to evaluate the transmutation rate of $W$, the effective neutron cross sections and the neutron fluxes of $W$ pin region for the use in ORIGEN2 [9], in which the specific activity of $\operatorname{Re}$ is calculated. Japanese evaluated nuclear data library, JENDL-4.0 [10] is used for base neutron cross sections except Re isotopes, which cross sections are derived from ENDF/B-7.0.

The one-point model burn-up code ORIGEN2 with one group cross section system is used for evaluating the specific activity of each isotope by applying the effective cross section and flux. In the original ORIGEN2 data library, cross sections for typical nuclear reactors are prepared, though some particular cross sections such as tungsten mixed with neutron moderator are not provided. Thus we have evaluated them by using MVP code.

In the treatment of neutrons, the interaction between particles is ignored and only the reactions with nuclei or atoms are considered. The particle behavior in the reaction of neutrons with nuclei or atoms is determined on the basis of the information of evaluated nuclear data files. In the case of the continuous-energy method by the Monte Carlo codes MVP, which we have employed, use the continuous-energy form of cross sections processed from the evaluated nuclear data files. The energy range for nuclear reactions and transport of neutrons is from $10^{-5} \mathrm{eV}$ to $20 \mathrm{MeV}$. All reactions given in the evaluated nuclear data files are treated explicitly in this energy range. The MVP cross section data files are generated for each nuclide from the evaluated nuclear data by using the LICEM code [11]. The data for the interpolation between temperatures are also included in the date files and thus cross sections at arbitrary temperatures are generated from the data. The microscopic cross sections are provided at fine energy mesh points in the generated libraries. These energy mesh points are selected so that the requested accuracy of linearized cross sections is satisfied (normally $0.1 \%$ ). The cross sections in the resolved resonance region are generated by the resonance formula given in the nuclear data file with the resonance parame- 


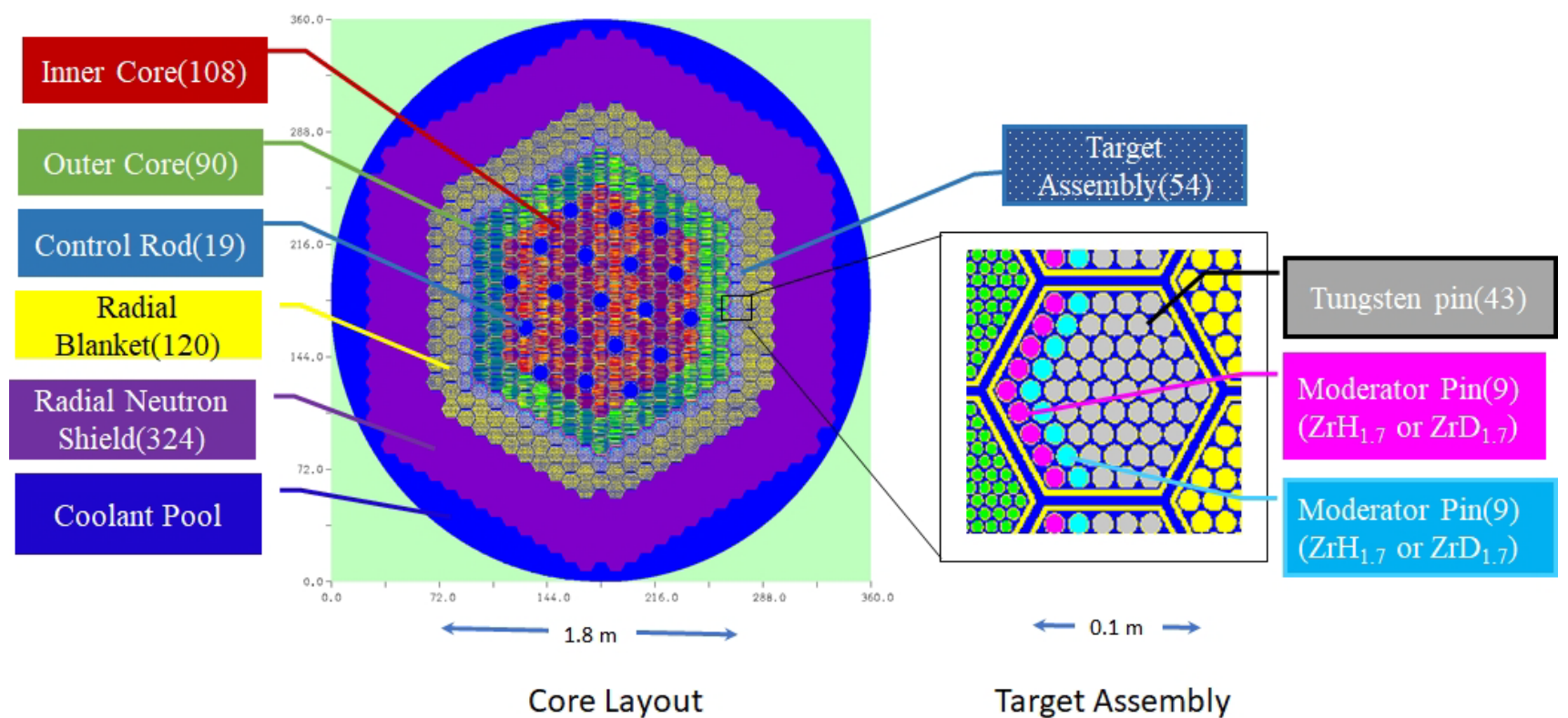

Figure 7: Core layout and target assembly model for MVP calculation.

ters. The cross sections between the given energy points are determined by the linear-linear interpolation. The cross sections in the unresolved resonance region are determined by the probability table method. In this method, the sets of capture, elastic scattering and fission cross sections and the probabilities for the sets are given and the cross sections are determined by random numbers.

In order to evaluate the core characteristics of fast reactor, a computer code system has been developed by utilizing the advanced analysis code MVP. The validity of MVP was verified by analyzing FBR MONJU experimental data obtained in the core physics tests. The differences between the results of MVP and the experimental data for major core characteristics such as criticality or control rod worth were $2 \%$ or less at the maximum [12].

In order to confirm the reliability the burn-up routine MVP-BURN, it was applied to the burn-up benchmark problems for a high conversion LWR lattice and a BWR lattice with burnable poison rods. The results of MVP-BURN have shown good agreements with those of a deterministic code for burn-up changes of infinite neutron multiplication factor, conversion ratio, power distribution, and number densities of major fuel nuclides. In the analysis, the results of these codes agreed with measured values within an error of $10 \%$ for most nuclides [13].

\section{Target Assembly Design and Modeling of}

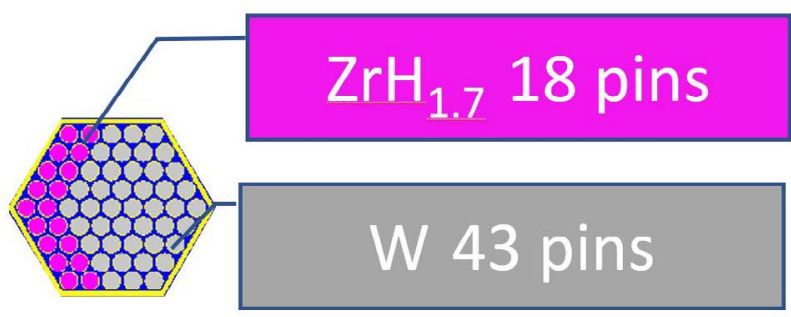

Figure 8: Pin layout of target assemblies for Case 1.

\section{the Core for MVP Calculation}

The core layout and the pin layout of the target assembly modeled for MVP calculation are shown in Figure 7.

We assumed five types of pin layout for the target assembly illustrated at the right hand in Figure 3 for studying the effect of neutron moderators on the transmutation for the difference of the cross sections between proton and deutron will affect the neutron energy spectra at the tungsten pins.

The pin layout cases are listed in Table 4 and illustrated in Figure 8, Figure 9, Figure 10, Figure 11 and Figure 12. For Case 1 to Case 4, outer 43 pins contain tungsten (W) pellets, which axial stack length is $930 \mathrm{~mm}$.

The pin layout with 18 zirconium hydride $\left(\mathrm{ZrH}_{17}\right)$ pins facing the core is tested for emphasizing strong neutron moderation effect in Case 1, while the pin layout with 18 zirconium deuteride 


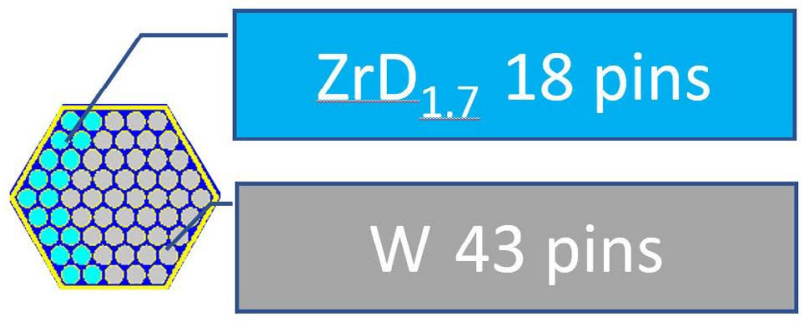

Figure 9: Pin layout of target assemblies for Case 2.

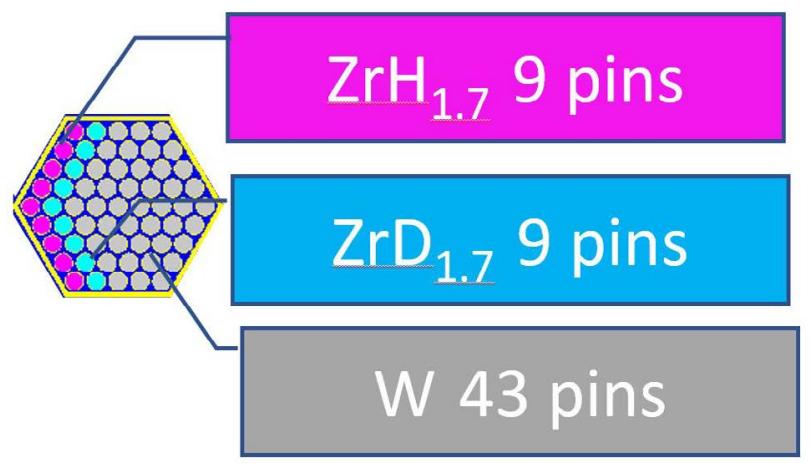

Figure 10: Pin layout of target assemblies for Case 3.

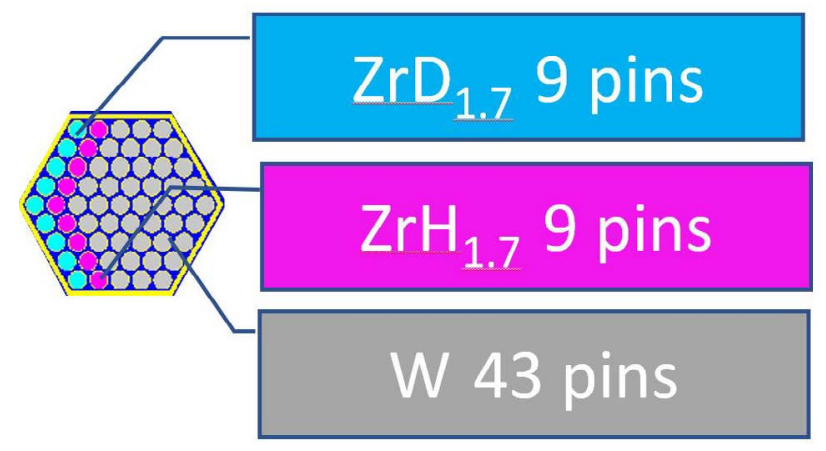

Figure 11: Pin layout of target assemblies for Case 4.

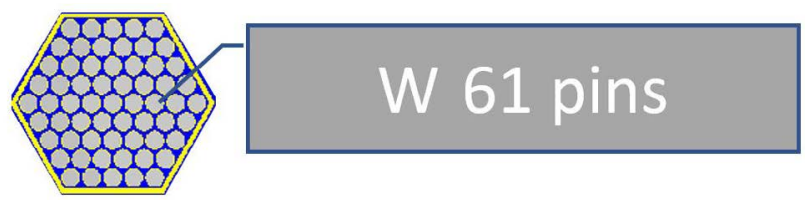

Figure 12: Pin layout of target assemblies for Case 5.

$\left(\mathrm{ZrD}_{1.7}\right)$ pins for weak moderation and absorption effect is done in Case 2, and the mixed moderator effects with the order of the moderators are tested in Case 3 and Case 4.

In Case 5, all 61 pins are set as tungsten pins.

The number of the target assemblies are 54 in total, which are located at the first row of the radial blanket region of the original core. The location of the target assembly is just outside of the core because the neutron moderator in the target assembly will affect the core performances through the softer neutron spectrum, which may decrease the number of fission neutrons emitted.

At the modeling of the whole core for the MVP calculation, we employed three dimensional model as is except the peripheral region such as neutron shield. The detailed dimensions of each core components and the composition of materials included are listed in Table 1 and Table 2. The height of the active core is set at $930 \mathrm{~mm}$; the upper/lower axial blanket thickness is set at $300 \mathrm{~mm} / 350 \mathrm{~mm}$; the length of the fission gas plenum is set at $1300 \mathrm{~mm}$. Thus the upper boundary of the model is set at the top of the gas plenum. The bottom boundary is set at the bottom of the lower shield $650 \mathrm{~mm}$ in length, which is located just below the lower axial blanket. The radial outer boundary is set at $1800 \mathrm{~mm}$ in radius, which is locate at the sodium coolant pool flooding the whole core components. The neutrons passing out the outer boundary are assumed to be lost from the system. For the burn-up calculation, MVP-BURN, the thermal power of the core is set at $710 \mathrm{MWt}$ for 3 year- burn-up cycles and each cycle is divided to two sub-cycles. Total neutron histories for each 6 steps are set at 1200000 , which are divided to 120 batches with 20 skip batches that means 20 bathes are skipped before the tally is started for Monte Carlo calculation.

MVP or MVP-BURN does not evaluate specific activity while ORIGEN-2 code do by using capture cross section and neutron flux, then we have calculated the capture cross sections of the nuclides and fluxes of the tungsten pin, which are provided in the output of MVP. One group average cross section is calculated by dividing the total reaction rate of nuclide over the whole energy by the total number density of the nuclide in MVP.

\section{Results and Discussion}

\section{Cross section and neutron flux at $\mathrm{W}$ region}

Table 4 lists the one group effective capture cross sections and neutron fluxes at the $W$ regions evaluated by MVP for the use of ORIGEN2, where specific reactivity is calculated. The effective cross sections of moderator applied cases, Case 1 to Case 4 increase by a few times that of no moderator case (Case 5), while the fluxes of these cases decrease 
Table 4: One group effective capture cross section and neutron flux at W region by MVP code.

\begin{tabular}{|c|c|c|c|c|c|c|c|c|c|}
\hline Case & Number of pins & Pin layout & ${ }^{182} W$ & ${ }^{183} W$ & ${ }^{184} \mathrm{~W}$ & ${ }^{186} \mathrm{~W}$ & ${ }^{185} \mathrm{Re}$ & ${ }^{187} \operatorname{Re}$ & Neutron flux \\
\hline & & & (barn) & (barn) & (barn) & (barn) & (barn) & (barn) & $\left(\mathrm{n} / \mathrm{cm}_{2} / \mathrm{s}\right)$ \\
\hline Case 1 & $\begin{array}{l}\mathrm{ZrH}_{1.7} 18 \text { pins } \\
\text { W } 43 \text { pins }\end{array}$ & Figure 8 & 0.574 & 1.203 & 0.237 & 0.580 & 9.348 & 4.823 & $7.57 E+14$ \\
\hline Case 2 & $\begin{array}{l}\mathrm{ZrD}_{1.7} 18 \text { pins } \\
\text { W } 43 \text { pins }\end{array}$ & Figure 9 & 0.268 & 0.792 & 0.230 & 0.176 & 2.355 & 2.361 & $1.09 E+15$ \\
\hline Case 3 & $\begin{array}{l}\mathrm{ZrH}_{1.7} 9 \text { pins } \\
\mathrm{ZrD}_{1.7} 9 \text { pins } \\
\mathrm{W} 43 \text { pins }\end{array}$ & Figure 10 & 0.418 & 1.053 & 0.235 & 0.365 & 6.255 & 4.138 & $8.79 E+14$ \\
\hline Case 4 & $\begin{array}{l}\mathrm{ZrD}_{1.7} 9 \text { pins } \\
\mathrm{ZrH}_{1.7} 9 \text { pins } \\
\text { W } 43 \text { pins }\end{array}$ & Figure 11 & 0.442 & 1.115 & 0.240 & 0.399 & 6.728 & 4.39 & $8.65 E+14$ \\
\hline Case 5 & $\begin{array}{l}\text { W } 61 \text { pins } \\
\text { (no moderator) }\end{array}$ & Figure 12 & 0.187 & 0.459 & 0.169 & 0.124 & 1.093 & 1.008 & $1.21 E+15$ \\
\hline \multicolumn{2}{|c|}{$\begin{array}{l}\text { Original ORLIBJ40 [11] } \\
\text { (infinite dilute model) }\end{array}$} & & 0.808 & 1.583 & 0.500 & 0.597 & 4.027 & 0.015 & - \\
\hline
\end{tabular}

Table 5: Production weight of Re after 3 years irradiation.

\begin{tabular}{|c|c|c|c|c|c|c|c|c|}
\hline Case & Number of pins & Pin layout & W load & Re weight & $\mathrm{Re} / \mathrm{W}$ & ${ }^{185} \mathrm{Re}$ & ${ }^{187} \operatorname{Re}$ & ${ }^{187} \mathrm{Re} /{ }^{185} \mathrm{Re}$ \\
\hline & & & $(\mathrm{kg})$ & (kg) & $(\%)$ & (kg) & (kg) & - \\
\hline Case 1 & $\begin{array}{l}\mathrm{ZrH}_{1.7} 18 \text { pins } \\
\text { W } 43 \text { pins }\end{array}$ & Figure 8 & 3.520 & 51.2 & 1.45 & 14.1 & 37.1 & 2.63 \\
\hline Case 2 & $\begin{array}{l}\mathrm{ZrD}_{1.7} 18 \text { pins } \\
\text { W } 43 \text { pins }\end{array}$ & Figure 9 & 3.520 & 40.3 & 1.14 & 23.6 & 12.7 & 0.54 \\
\hline Case 3 & $\begin{array}{l}\mathrm{ZrH}_{1.7} 9 \text { pins } \\
\mathrm{ZrD}_{1.7} 9 \text { pins } \\
\text { W } 43 \text { pins }\end{array}$ & Figure 10 & 3.520 & 44.4 & 1.26 & 17.6 & 27.8 & 1.58 \\
\hline Case 4 & $\begin{array}{l}\mathrm{ZrD}_{1.7} 9 \text { pins } \\
\mathrm{ZrH}_{1.7} 9 \text { pins } \\
W 43 \text { pins }\end{array}$ & Figure 11 & 3.520 & 45.6 & 1.30 & 17.3 & 27.2 & 1.57 \\
\hline Case 5 & $\begin{array}{l}\text { W } 61 \text { pins } \\
\text { (no moderator) }\end{array}$ & Figure 12 & 5.010 & 49.1 & 0.98 & 29.1 & 19.9 & 0.68 \\
\hline
\end{tabular}

by about 0.6 to 0.9 time that of Case 5 due to the neutron absorption by the protons or deuterons included in the moderators.

\section{Production of Re after 3 years irradiation}

The produced Re weights after 3 years irradiation in the core has been evaluated by MVP-BURN code. Table 5 lists the loaded $W$ weights, produced Re weights and the ratio of isotope fractions.
The produced Re weight at 3 years irradiation will be more than $50 \mathrm{~kg}$ in prototype reactor, which corresponds to about $1 \%$ of Japanese annual production of Re at present.

Figure 13 illustrates the effect of moderators on the cross sections and production of Re isotopes. The scattering cross section of proton is much larger than that of deuteron. Meanwhile, the resonance 


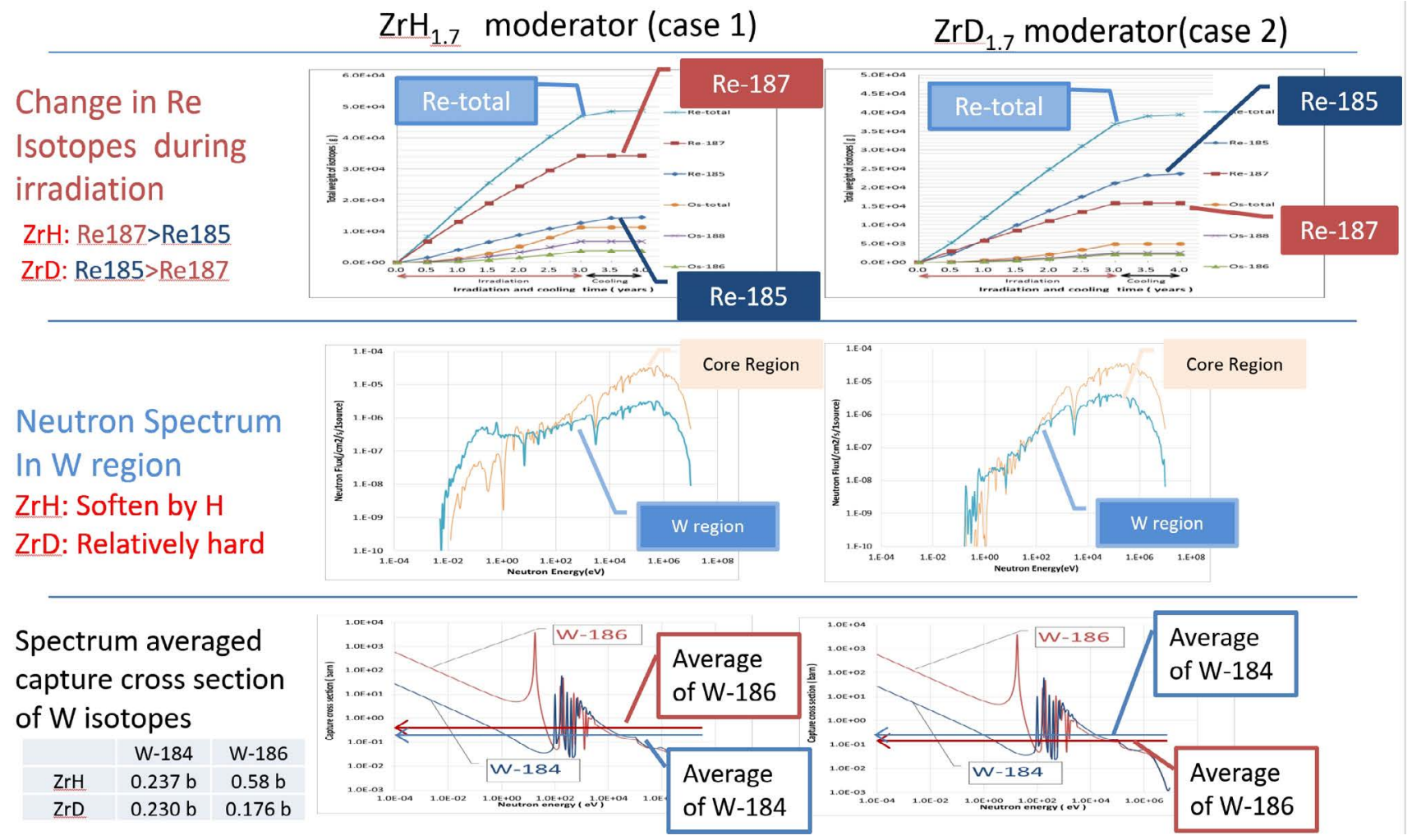

Figure 13: Comparison of ZrH1.7 (Case 1) and ZrD1.7 (Case 2) moderator.

Table 6: Exemption level of Re isotopes [5].

\begin{tabular}{|l|l|}
\hline Isotope (Half life) & $\mathbf{B q} / \mathbf{g}$ \\
\hline${ }^{186} \mathrm{Re}$ & $1 \times 10^{3}$ \\
\hline$(3.8 \mathrm{~d})$ & $1 \times 10^{6}$ \\
\hline${ }^{187} \mathrm{Re}$ & \\
\hline$\left(5 \times 10^{10} \mathrm{y}\right)$ & $1 \times 10^{2}$ \\
\hline$(17 \mathrm{~h})$ & \\
\hline
\end{tabular}

capture peaks of ${ }^{184} \mathrm{~W}$ are positioned at relatively higher energy than that of ${ }^{186} \mathrm{~W}$. Therefore the softer neutron spectrum induced by $\mathrm{ZrH}_{1.7}$ in Case 1 makes the energy averaged effective cross section of ${ }^{186} \mathrm{~W}$ much higher than that of Case $2\left(\mathrm{ZrD}_{1.7}\right.$ moderator) while the effective cross sections of ${ }^{184} \mathrm{~W}$ of the both cases are almost the same. Thus the weight of ${ }^{187} \mathrm{Re}$ is larger than that of ${ }^{185} \mathrm{Re}$ in Case 1 ( $\mathrm{ZrH}$ moderator) while ${ }^{185} \mathrm{Re}$ produced from ${ }^{184} \mathrm{~W}$ is larger than ${ }^{187} \mathrm{Re}$ in Case 2. For Case 3 and Case 4, the ratio of ${ }^{187} \mathrm{Re} /{ }^{185} \mathrm{Re}$ is in the middle of the Case 1 and Case 2 as shown in the last column of Table 5. For no-moderator case (Case 5), the ratio of ${ }^{187} \mathrm{Re} /{ }^{185} \mathrm{Re}$ is almost same as that of Case 2 and the Re production rate per loaded $\mathrm{W}$ is smaller than that of Case 2 as shown in the sixth column of
Table 6.

\section{Specific activity of Re}

The specific activity of Re during irradiation and cooling has been evaluated by ORIGEN2 with the cross section and flux shown in Table 4.

Figure 14 shows the specific activities of the isotopes of $\mathrm{W}, \mathrm{Re}$, and osmium (Os) in Case 1, in which the produced $\mathrm{Re}$ is the maximum among the evaluated cases. The exemption levels of Re isotopes determined by IAEA [5] are listed in Table 7.

As shown in Figure 14, the main radioactivity of Re is that of ${ }^{188} \operatorname{Re}$, the daughter of ${ }^{188} \mathrm{~W}$, during the cooling time if $\mathrm{W}$ and Re are not separated after the irradiation. The specific activity of ${ }^{188} \mathrm{Re}$ is 6 decades higher than that of the exemption level. If $W$ and $R e$ is separated after the irradiation, radioactivity of most $\mathrm{Re}$ isotopes are negligible as shown in Figure 15.

Thus the exemption level of Re specific activity is easily achieved in a half year cooling in case the separation of $\mathrm{W}$ from $\mathrm{Re}$ is conducted.

\section{Specific activity for different moderators}

Figure 16 illustrates the specific activity of Re for different types of moderators when Re is separat- 


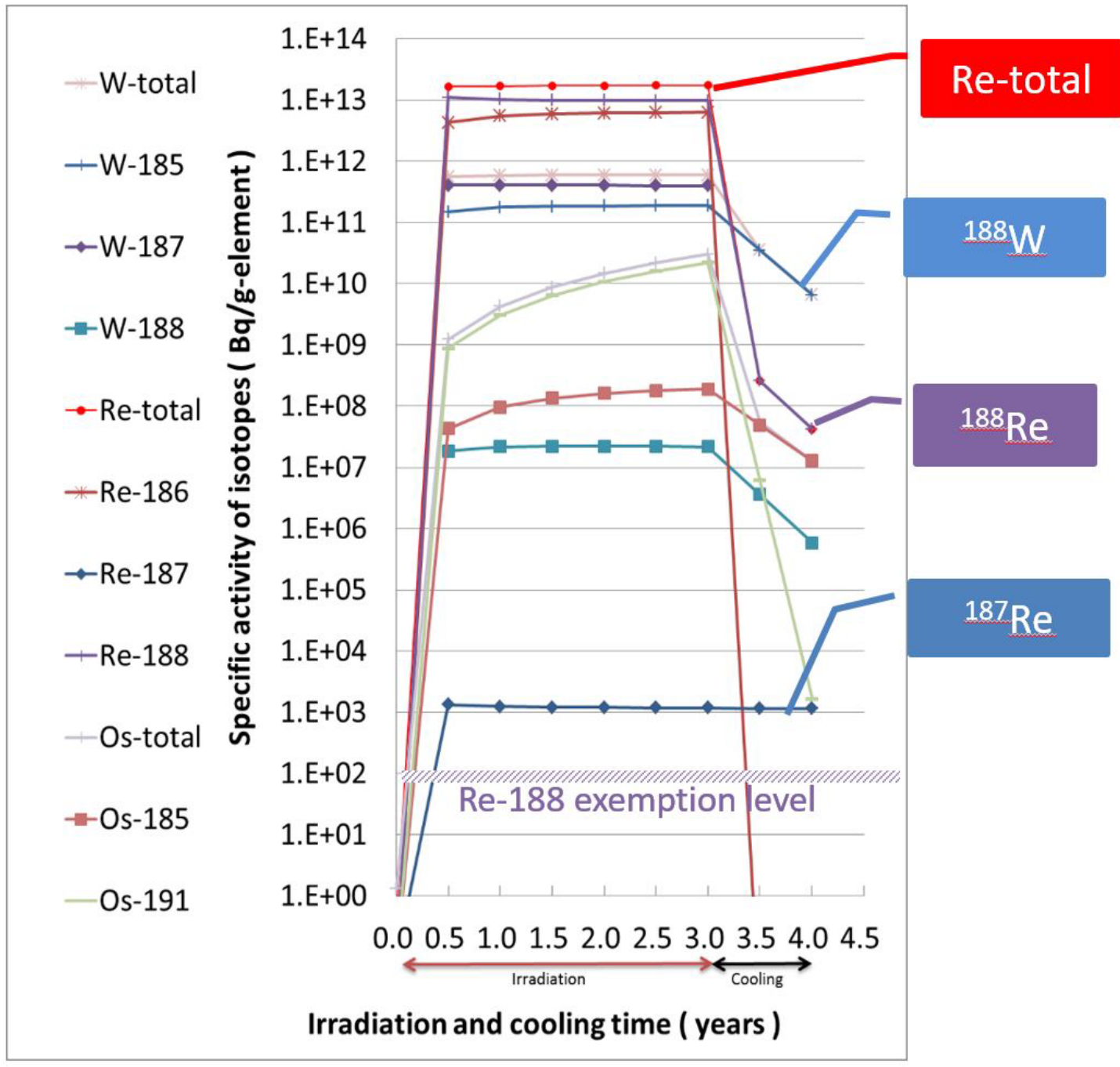

Figure 14: Specific activity when Re is not separated from W.

Table 7: Specific activity of Re and natural Re.

\begin{tabular}{|c|c|c|c|c|c|}
\hline Case & Number of pins & Pin layout & Specific activity & Produced Re weight & $\mathrm{Re} / \mathrm{W}$ \\
\hline & & & $(\mathrm{Bq} / \mathrm{g})$ & $(\mathrm{kg})$ & $(\%)$ \\
\hline Case 1 & $\begin{array}{l}\mathrm{ZrH}_{1.7} 18 \text { pins } \\
\text { W } 43 \text { pins }\end{array}$ & Figure 8 & 1150 & 51.2 & 1.45 \\
\hline Case 2 & $\begin{array}{l}Z_{1.7} 18 \text { pins } \\
\text { W } 43 \text { pins }\end{array}$ & Figure 9 & 658 & 40.3 & 1.14 \\
\hline Case 3 & $\begin{array}{l}\mathrm{ZrH}_{1.7} 9 \text { pins } \\
\mathrm{ZrD}_{1.7} 9 \text { pins } \\
\text { W } 43 \text { pins }\end{array}$ & Figure 10 & 1004 & 44.4 & 1.26 \\
\hline Case 4 & $\begin{array}{l}\mathrm{ZrD}_{1.7} 9 \text { pins } \\
\mathrm{ZrH}_{1.7} 9 \text { pins } \\
\text { W } 43 \text { pins }\end{array}$ & Figure 11 & 1033 & 45.6 & 1.30 \\
\hline Case 5 & $\begin{array}{l}\text { W } 61 \text { pins } \\
\text { (no moderator) }\end{array}$ & Figure 12 & 938 & 49.1 & 0.98 \\
\hline Natural Re & - & - & 1050 & - & \\
\hline
\end{tabular}




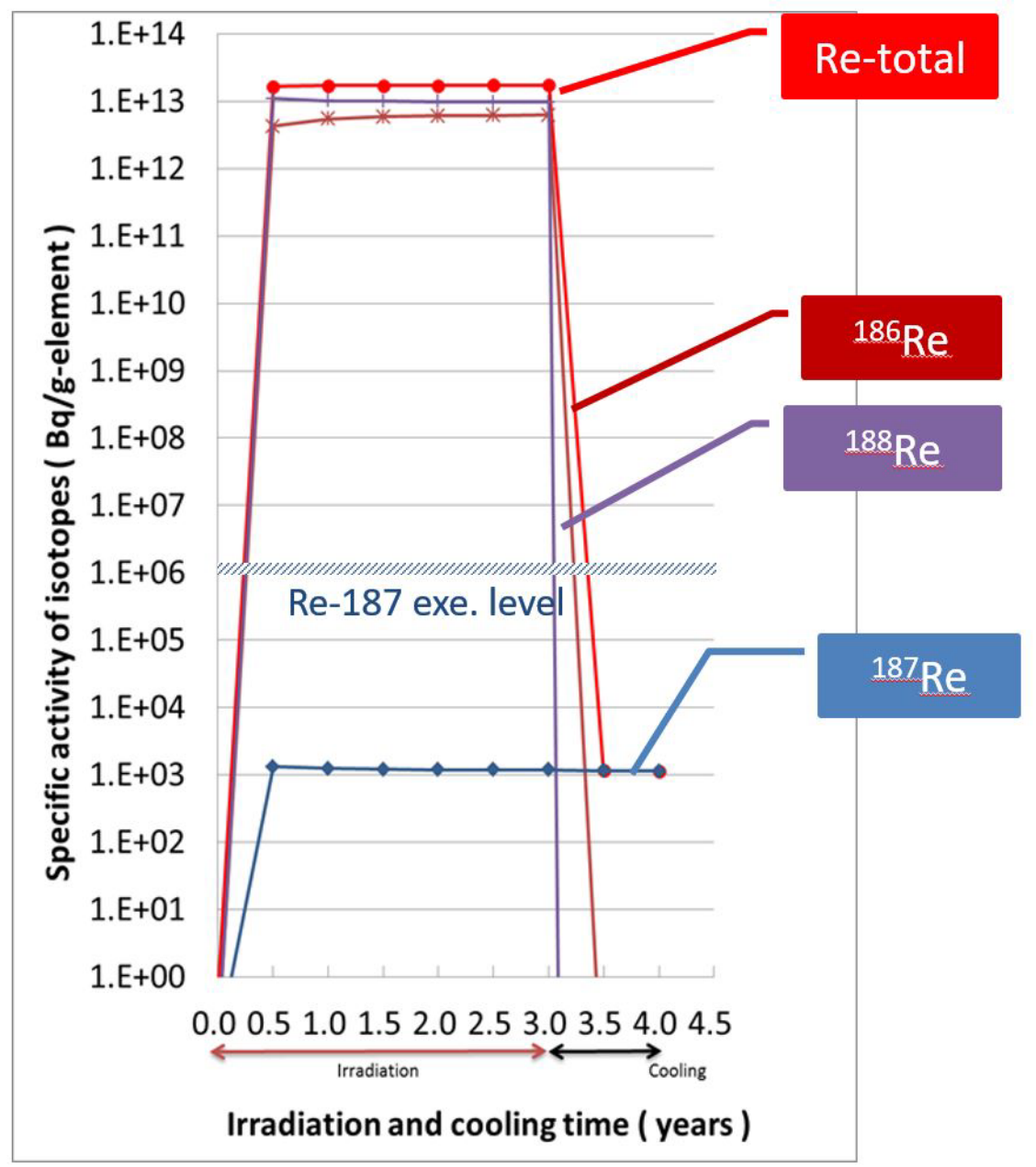

Figure 15: Specific activity when Re is separated from $W$ and Os after irradiation.

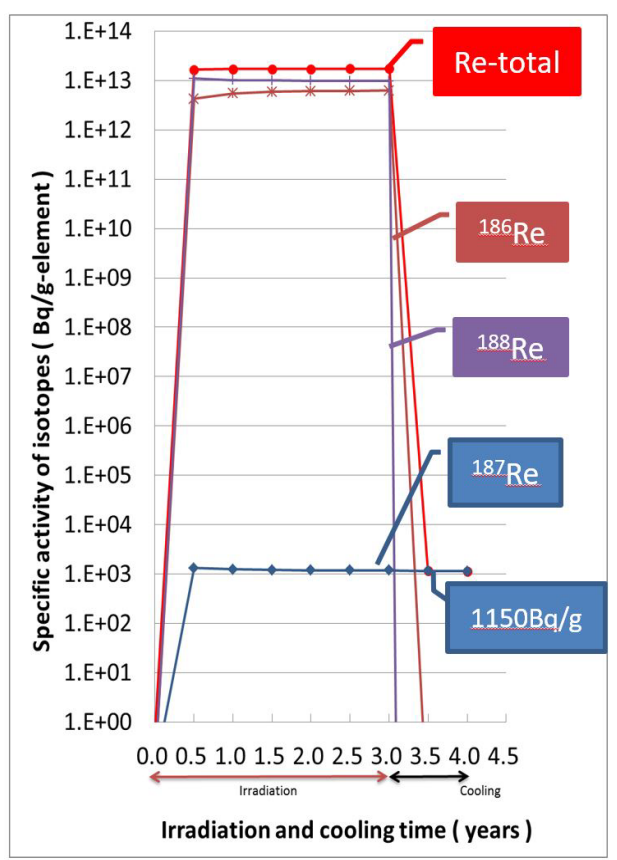

$\mathrm{ZrH}_{1.7}$ moderator (Case 1)

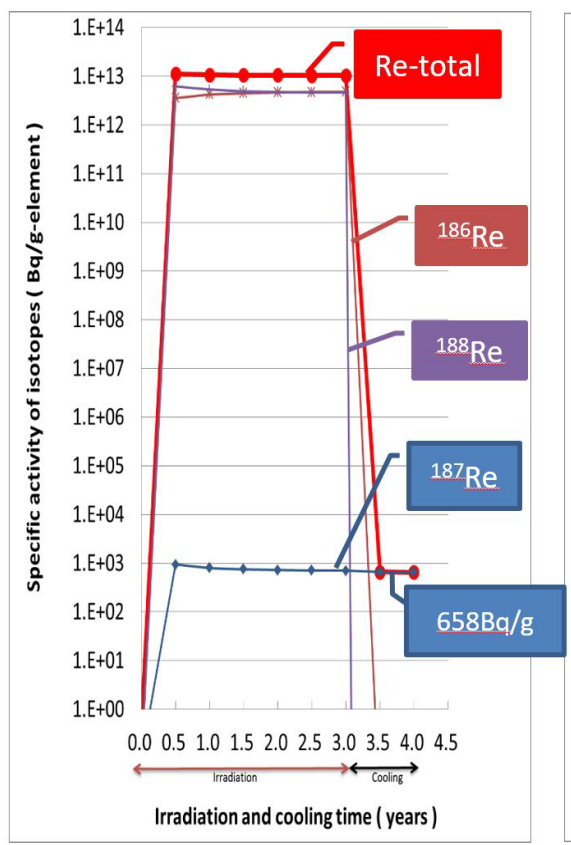

$\mathrm{ZrD}_{1.7}$ moderator (Case 2) No moderator( Case 5)

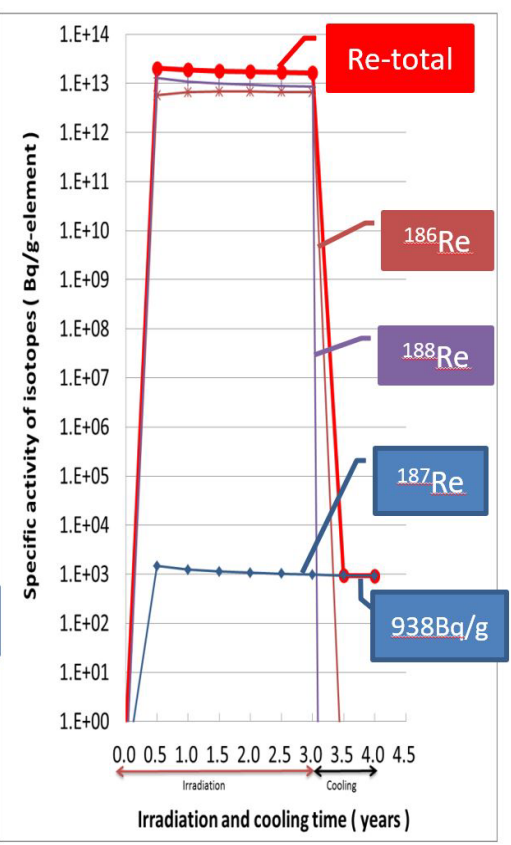

Figure 16: Specific activity of Re vs. types of moderator. 


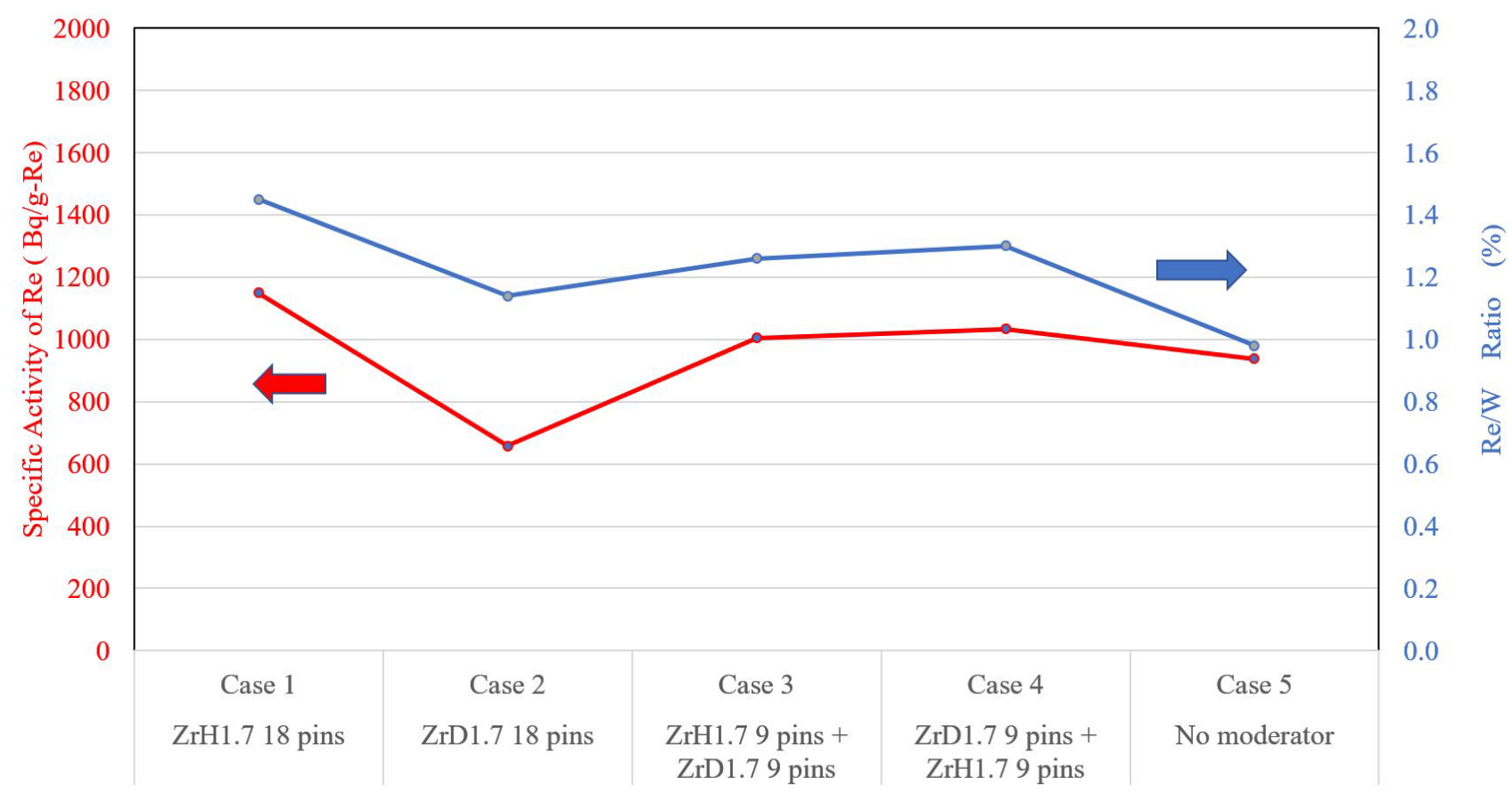

Figure 17: Specific activity of Re and Re to $W$ ratio vs. types of moderator.

ed from $\mathrm{W}$ and Os after the irradiation. The use of $\mathrm{ZrD}_{1.7}$ (Case 2 reduces the specific activity by half compared to that of $\mathrm{ZrH}_{1.7}$ (Case 1) or no moderator (Case 5) due to the decrease of the fraction of ${ }^{187} \mathrm{Re}$ $\left(T_{1 / 2}=4.3 \times 10^{10}\right.$ years $)$.

The comparison of specific activity of each case and natural $R e$ is listed in Table 7. The specific activities of Re for the mixed moderator cases (Case 3 and Case 4) are intermediate values between that of Case 1 and Case 2.

The specific activity of produced Re is less than that of natural $\operatorname{Re}(1050 \mathrm{~Bq} / \mathrm{g}$-Re, the abundance of $\left.{ }^{187} \mathrm{Re}: 62.6 \%\right)$, which suggests the no moderator case seems acceptable, though the production ratio ( $\mathrm{Re} / \mathrm{W}$ ratio) is lower than other cases as shown in Figure 17. This figure suggests that Case 2 is more preferable than Case 5 if the production efficiency of Re per loaded $W$ is crucial if emphasizing the system economy.

\section{Reprocessing and the separation of Re from $\mathbf{W}$}

After the completion of the irradiation of $W$ in the fast reactor, $\mathrm{Re}$, the main transmutation product of W, is discharged with the target assemblies, then will simultaneously be reprocessed with Spent Fuel (SF). In the PUREX reprocessing, Re and remained $\mathrm{W}$ may form possibly oxo anions $\mathrm{ReO}_{4}^{-}$and $\mathrm{WO}_{4}{ }^{2-}$ in the dissolver solution. These will be co-ex- tracted with $\mathrm{UO}_{2}{ }^{2+}$ and $\mathrm{Pu}^{4+}$ in replacing one $\mathrm{NO}_{3}$ anion. In the case of $\mathrm{ReO}_{4}^{-}$, for instance,

$$
\mathrm{UO}_{2}{ }^{2+}+\mathrm{ReO}_{4}^{-}+\mathrm{NO}_{3}^{-}+2 \mathrm{TBP}=\mathrm{UO}_{2}\left(\mathrm{ReO}_{4}\right) \mathrm{NO}_{3} \cdot
$$
2TBP.

Since $\mathrm{ReO}_{4}^{-}$and $\mathrm{WO}_{4}^{2-}$ are known to express almost the same distribution characteristic (D vs. $\mathrm{HNO}_{3}$ ) as that of $\mathrm{TcO}_{4}^{-}$for TBP, they might be distributed to the whole extraction cycles as the same manner as $\mathrm{TcO}_{4}^{-}$[14], and finally be concentrated in the high-level liquid waste (HLLW). Therefore, it is obvious to investigate Re recovery from the HLLW. The typical electrode reactions with $E^{O}$ of $\mathrm{Re}, \mathrm{W}$ and $\mathrm{Tc}$ in acidic solution are shown as follows;

$$
\begin{aligned}
& \mathrm{WO}_{4}{ }^{2-}+4 \mathrm{H}_{2} \mathrm{O}+6 \mathrm{e}=\mathrm{W}+8 \mathrm{OH}^{-} E^{O}=-1.05 \mathrm{~V} \\
& \mathrm{ReO}_{4}{ }^{-}+8 \mathrm{H}^{+}+7 \mathrm{e}=\mathrm{Re}+4 \mathrm{H}_{2} \mathrm{O} E^{O}=+0.362 \mathrm{~V} \\
& \operatorname{ReO}_{4}{ }^{-}+4 \mathrm{H}^{+}+3 \mathrm{e}=\mathrm{ReO}_{2}+2 \mathrm{H}_{2} \mathrm{O} E^{O}=+0.510 \mathrm{~V} \\
& \mathrm{ReO}_{4}{ }^{-}+2 \mathrm{H}^{+}+\mathrm{e}=\mathrm{ReO}_{3}+2 \mathrm{H}_{2} \mathrm{O}^{O}=+0.732 \mathrm{~V} \\
& \mathrm{TcO}_{4}^{-}+8 \mathrm{H}^{+}+7 \mathrm{e}=\mathrm{Tc}+4 \mathrm{H}_{2} \mathrm{O}^{O}=+0.472 \mathrm{~V} \\
& \mathrm{TcO}_{4}{ }^{-}+4 \mathrm{H}^{+}+3 \mathrm{e}=\mathrm{TcO}_{2}+2 \mathrm{H}_{2} \mathrm{O}^{O}=+0.738 \mathrm{~V}
\end{aligned}
$$

The large $\Delta E^{0}$ between $\mathrm{ReO}_{4}^{-}$or $\mathrm{TcO}_{4}^{-}$and $\mathrm{WO}_{4}{ }^{2-}$ suggests the preferential deposition of $\mathrm{Re}$ or Tc by the electrolytic extraction (EE) method; When polarizing the electrode potential to CA. 0 to $0.3 \mathrm{~V}$ (V vs. SHE) for instance, Re and Tc will 


\section{Electrodes: ' smooth $\cdot \mathrm{Pt}, \cdot$ cathode $\cdot\left(2 \mathrm{~cm}^{2}\right), \cdot$ anode $\cdot\left(8 \mathrm{~cm}^{2}\right) \cdot, \cdot \mathrm{RE}: \cdot \mathrm{Ag} / \mathrm{AgCl}$, Catholyte: $\cdot 0.5 \mathrm{MHCl}, \cdot \mathrm{Tc}_{\mathrm{conc}}: \cdot 50 \mathrm{ppm}, \cdot \mathrm{Re}_{\mathrm{conc}} . \cdot 200 \mathrm{ppm}, \cdot \mathrm{Temp}: \cdot 50^{\circ} \mathrm{C}, \cdot \mathrm{Ic} ; \cdot$ $2.5 \mathrm{~mA} / \mathrm{cm} 2 \cdot(1 \mathrm{hr}) \rightarrow \cdot 75 \mathrm{~mA} / \mathrm{cm} 2 \cdot(2 \mathrm{hr}) \cdot \rightarrow \cdot 100 \cdot \mathrm{mA} / \mathrm{cm} 2 \cdot(4 \mathrm{hr}) \Phi$}
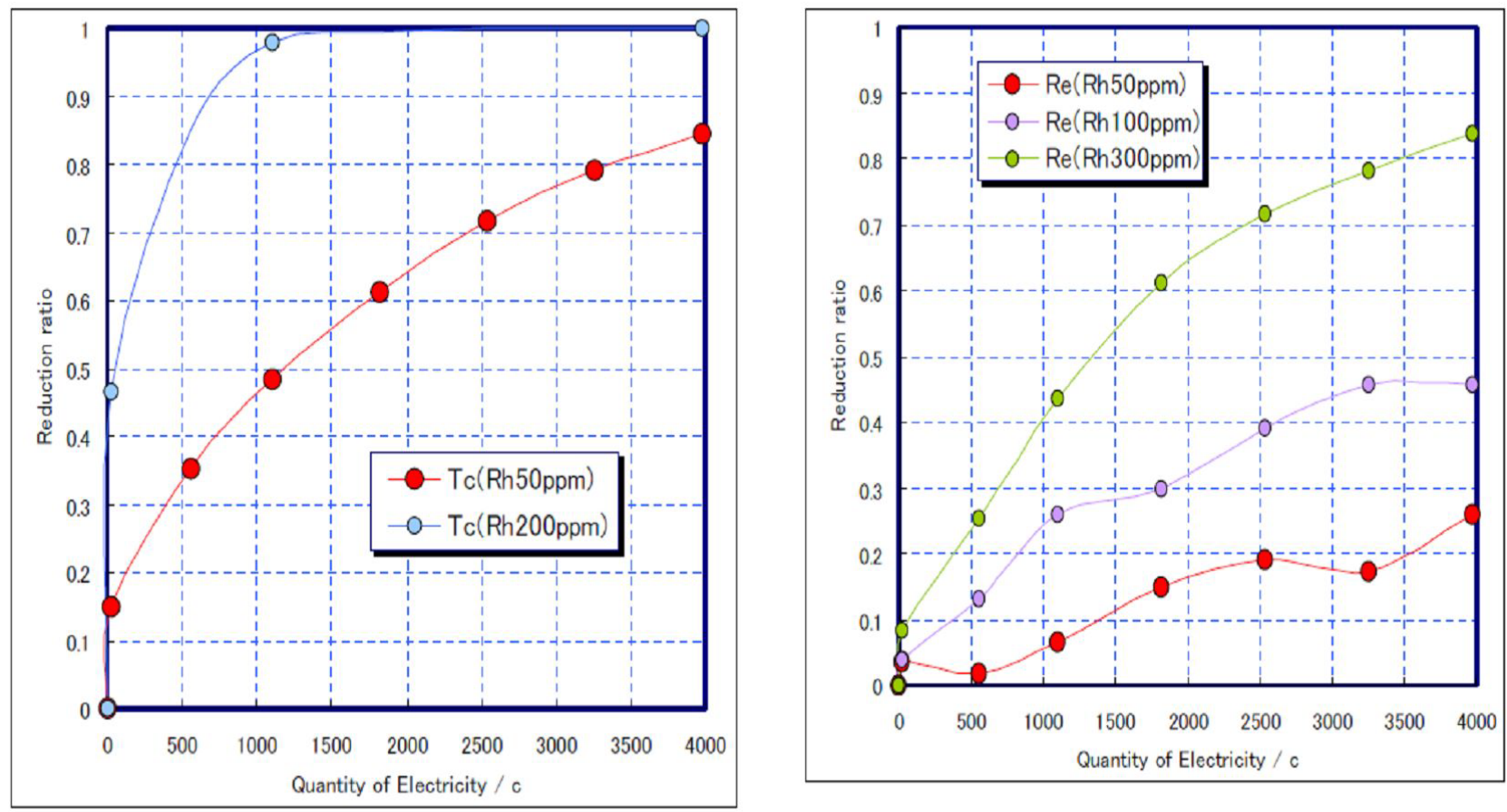

Figure 18: UPD effect on the deposition of Re and Tc by adding Rh3+ Galvanostatic electrolysis.

deposit on the cathode mostly in oxide state with leaving oxo anion $\mathrm{WO}_{4}{ }^{2-}$ in the HLLW. As shown the galvanostatic EE in Figure 18, deposition yields of Re and Tc can significantly be increased by adding $\mathrm{Rh}^{3+}$ originally co-presented in the HLLW [15]. Such a deposit acceleration is explained by the under potential deposition (UPD) brought by $\mathrm{Rh}_{\text {adatom }}$. UPD by $\mathrm{Pd}_{\text {adatom }}$ was also significant on $\mathrm{Ru}$ deposition. While the $f$-element groups of actinides and lanthanides are separable due to electrochemical basic properties, some $d$-element PGM, Ru, Rh, Pd and Os having nobler $E^{O}$ (e.g., Rh: $0.80 \mathrm{~V}, \mathrm{Pd}: 0.987 \mathrm{~V}$, Os: $0.7 \mathrm{~V})$, must accompany with Re during the $\mathrm{EE}$ process.

Figure 19 shows the distribution ratios (D) of the elements composing the HLLW on macrocyclic $\mathrm{B} 18 \mathrm{C} 6$ resin [16]. In this $5 \mathrm{M} \mathrm{HCl}$ condition for instance, the high separation of PGM can be is expected with $\mathrm{SF}_{\mathrm{Re} / \mathrm{PGM}}>100$ by the ion-exchange (IX) method.

Namely, the combinatorial separation by EE and
IX processes will ensure the promising recovery and refining of $\operatorname{Re}$ from $W$, fission products and actinides in the HLLW. The mutual separation of Re and Tc must be the issue.

\section{Conclusions}

The feasibility of rhenium (Re) production by irradiating tungsten (W) metal in a medium size fast reactor was evaluated by using the Monte Carlo calculation code MVP and ORIGEN2. The prototype fast reactor can produce about 50 kilograms of $\mathrm{Re}$ perevery 3 years, which corresponds to about $1 \%$ of Japanese domestic consumption. The specific activity of Re can be reduced below the exemption level or even the natural Re level if $\mathrm{W}$ and osmium (Os) are separated after the irradiation. The use of $\mathrm{ZrD}_{1.7}$ moderator reduces the specific activity to half that of $\mathrm{ZrH}_{1.7}$ moderator case, and even the no moderator case is acceptable if the specific activity of Re produced in fast reactors should be less than that of natural Re. 


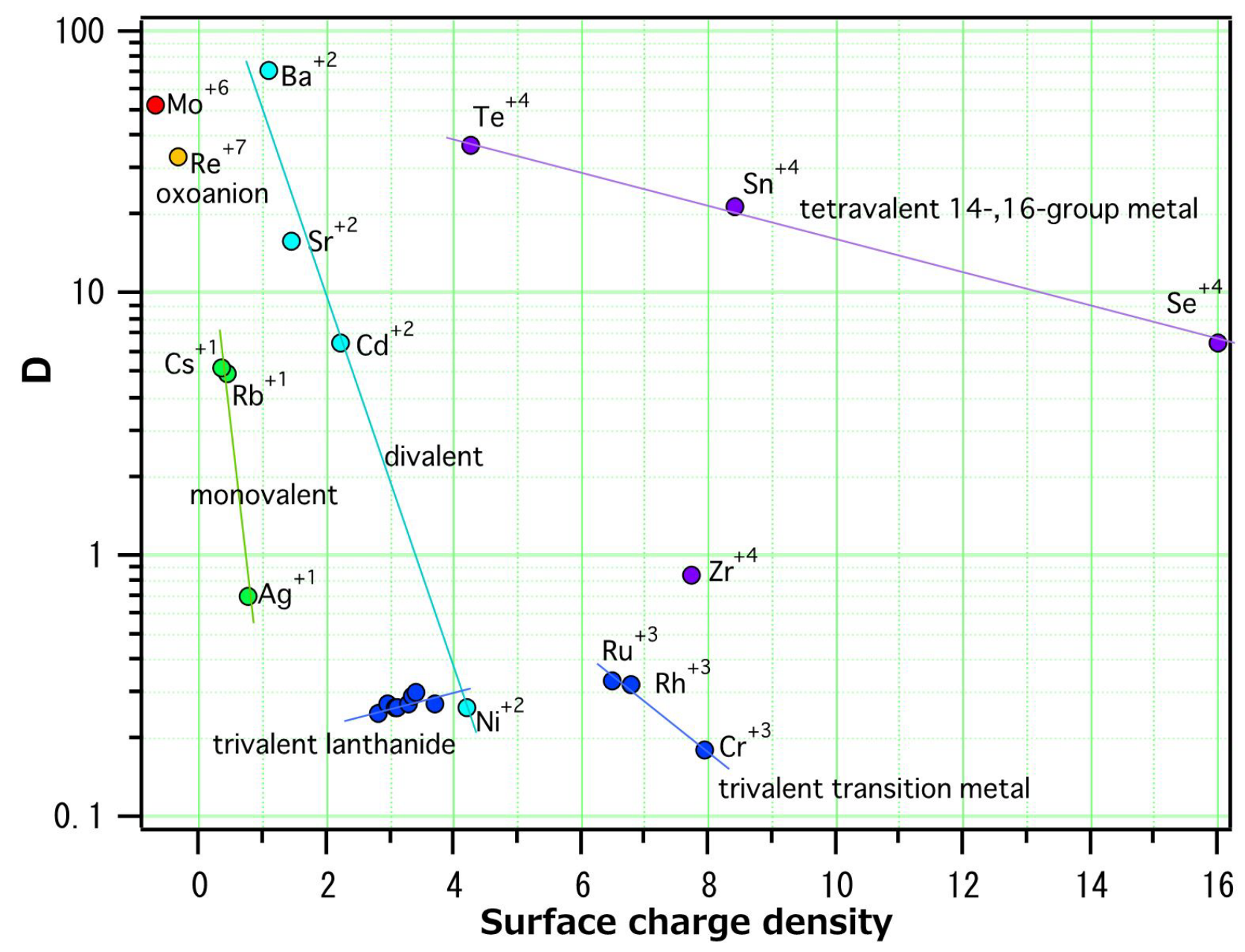

Figure 19: Relation between $D$ and Surface charge density $(\mathrm{Cr} 2)$ on metal ions for Macro-cyclic B18C6 resin$5 \mathrm{MHCl}-$ simu.

\section{References}

1. Alan E Waltar, Donald R Todd, Pavel V Tsvetkov (2012) Fast Spectrum Reactor. Springer.

2. Han CY, Ozawa M, Saito M (2012) Resource ability on nuclear fuel cycle by transmutation approach. Science China Chemistry 55: 1746-1751.

3. Ozawa M, Han CY, Kaneshiki T, Nilsson M (2013) Après ORIENT, a P\&T-Based New Resource Strategy in Nuclear Fuel Cycle. In Proceedings of the International Nuclear Fuel Cycle Conference (GLOBAL 2013) 1499-1503.

4. Terashima A, Ozawa M (2015) Numerical analysis on element creation by nuclear transmutation of fission products. Nuclear Science and Techniques 26: s010311.

5. Yokoyama T, Terashima A, Ozawa M (2014) Evaluation of rhenium production rates in tungsten irradiated in fast reactors by using continuous energy monte carlo code MVP. In Proceedings of the 8th International
Symposium on Technetium and Rhenium: Science and Utilization (ISTR2014) 526-532.

6. IAEA (International Atomic Energy Agency) (2014) Radiation Protection and Safety of Radiation Sources: International Basic Safety Standards. IAEA Safety Standard Series No. GSR Part 3.

7. Nagaya Y, Okumura K, Mori T, Nakagawa M (2015) MVP/GMVP II: General purpose monte carlo codes for neutron and photon transport calculations based on continuous energy and multigroup methods. JAERI (Japan Atomic Energy Research Institute) JAERI1348.

8. Okumura K, Mori T, Nakagawa M, Kaneko K (2000) Validation of a continuous-energy monte carlo burnup code MVP-BURN and its application to analysis of post irradiation experiment. Journal of Nuclear Science and Technology 37: 128-138.

9. Okumura K, Sugino K, Kojima K, Jin T, Okamoto T, et al. (2013) A set of ORIGEN2 cross section libraries based on JENDL-4.0: ORLIBJ40. JAEA (Japan Atomic 
Energy Agency), JAEA-Data/Code 2012-032.

10.Shibata K, Iwamoto O, Nakagawa T, Iwamoto $\mathrm{N}$, Ichihara A (2011) JENDL-4.0: A new library for nuclear science and engineering. Journal of Nuclear Science and Technology 48: 1-30.

11.Mori T, Nakagawa M, Kaneko K (1996) Neutron Cross section library production code system for continuous energy monte carlo code MVP. LICEM. JAERI-Data/Code 96-018.

12.T Nakajima, H Endou, T Yokoyama (2008) A computer code system arcadia for fast reactor core analysis and applications. Proc of International Conference on the Physics of Reactors (Physor2008) 2338-2345.

13.Keisuke OKUMURA, Takamasa MORI, Masayuki NAKAGAWA, Kunio KANEKO (2000) Validation of a continuous-energy monte carlo burn-up code MVP-burn and its application to analysis of post irradiation experiment. Journal of Nuclear Science and Technology 37: 128-138.

14.M Ozawa, M Ishida, Y Sano (2003) Strategic Separation of Technetium and Rare Metal Fission Products in Spent Nuclear Fuel: Solvent Extraction Behavior and Partitioning by Catalytic Electrolytic Extraction. Radiochemistry 45: 225-232.

15. Masaki Ozawa, Shinichi Koyama, Tatsuya Suzuki (2009) Potentiality and reality on recycle of nuclear rare metals as a new resource for the next generation. Proceedings of R'09 Twin World Congress (CD-ROM).

16. Masaki Ozawa (2015) Après ORIENT cycle, A resourceoriented P\&T program on fission products. The 3rd Japan-China Academic Symposium on Nuclear Fuel Cycle (ASNFC2015), Tokyo, Japan. 